\title{
Using an AUV for Assessing Wastewater Discharges Impact: An Approach Based on Geostatistics
}

\author{
AUTHORS \\ Patrícia Ramos \\ Institute for Systems and Computer \\ Engineering of Porto (INESC Porto) \\ and Polytechnic Institute of Porto \\ Nuno Abreu \\ Institute for Systems and Computer \\ Engineering of Porto (INESC Porto)
}

\section{Introduction}

\section{Tot Twaters are often discharged inted stal waters through outfall dif-} fusers that efficiently dilute effluent and usually restrict any environmental impact within a small area. However, predicting this impact is difficult because of the complexity of the hydrodynamic processes that mix the wastewater and also because of the variability in oceanic conditions. Despite great improvements over the years in the understanding of these mixing processes, since models are now available that can make reasonable predictions under steady-state conditions (Roberts et al., 2002), many aspects remain unknown and unpredictable. For this reason, much efforr has been recently devored to improve ways of monitoring and characterizing sewage plumes under a variety of oceanographic conditions.

\section{Wastewater Plume Detection}

Basically, there are three ways of detecting diluted wastewater in marine waters: bottle sampling, natural tracer tracking, and artificial tracer tracking.

\section{A B S T R A C T}

Several monitoring approaches have been used to understand the physical, chemical, and biological processes associated with coastal sewage discharges. However, these efforts have not improved the understanding of the interaction of effluent plume/coastal ocean processes. Autonomous undenwater vehicles (AUVs) have already bieen shown to be very useful for performing high-resolution surveys of small features such as outtall plumes. Some of the advantages of these platforms include easier field logistics, low costtper deployment, good spatial coverage, sampling over repeated sections, and the ability to perform feature-based or adaptive sampling. Once the data have been collected in the field, itismecessany to extrapolate from monitoring samples to unsampled locations, Geostatistics has been successfully used to obtain information; for example, regarding the spatial distribution of soil properties. Besides giving estimated values at unsampled locations, it provides a measure of the accuracy of the estimate, which is a significant advantage over traditional methods used to assess pollution. In this work, geostatistics is used to model and map the spatial distribution of temperature measurements gathered by an AUV in a sea outtall menitoring campaign, with the aim of distinguishing the effluent plume from the receiving waters and characterizing its spatial variability in the vicinity of the discharge. The results demonstrate that this methodology can provide good estimates of the dispersion of effluent, and it is therefore very valuable in assessing the environmental impact and managing sea outialls.

Keywords: sewage outfalls mapping, geostatistics, assessment of wastewater discharges, autonomous underwater vehicles

Bortle sampling is the most traditional and widespread detection technique. Periodically, several water samples are collected on a predetermined three-dimensional grid, in the vicinity of the outfall and/or at shoreline stations, and brought back to the laboratory to be analyzed for microbiological parameters, heavy metals, etc. In situ techniques can usually derect physical, bio-optical, and chemical characteristics of the plume, but they do not directly detect the contaminating components of the waste- field such as fecal pathogens, heavy metals, or organic compounds. Bottle sampling, in contrast to in situ techniques, can provide information on potential risk indicators, but it does not allow real-time plume detection and lacks high spatial and/or temporal resolution, because it is usually limired to a few discrete points. Detection of wastewater can in principle be accomplished using the natural tracers associated with the effluent. Several field studies measuring temperature, salinity, turbidity, and chlorophyll 
fluorescence were performed to characterize and determine the spatial extent of sewage plumes (Washburn, 1992; Wu et al., 1994; Petrenko et al., 1998; Jones et al., 2001; Ramos et al., 2007; Ramos \& Neves, 2009). In these cases, sewage plumes were distinguished from background waters by low salinity, high turbidity, low temperature, and low chlorophyll fluorescence. The limitations of this technique include difficulty in detecting surfacing plumes, limited range of detection, and low signal-to-noise ratios in environments with large gradients in background values of the natural tracer. Nonetheless, it is still one of the easiest techniques used for the detection of sewage plumes when improvement in sampling of contaminared areas is necessary and a quicker response in case of contamination risks to nearby beaches is required. When a source point, as a sewage plume, is under investigation and several doubrs with regards to the environmental impact need to be clarified, detection methods using introduced tracer substances are usually used (Carvalho et al., 2002; Roberts et al., 2002; Hunt et al., 2010). These include radioactive tracers, fluorescent dyes, or particles, which are injected into the effluent, either at the treatment plant or at the level of the diffusers in the waters. These methods involve extensive preparation (the study of potential interferences with the tracer, which in the case of fluorescence includes changing remperatures, photochemical decay, biodegradation, degradation by chlorine, etc., not forgetting the calibration coefficients of the sensors used to measure the dye at the Wastewater treatment plant [WWTP] and offshore), high tracer costs, coordination with cruise time, and potentially negative impacts on the environment. Principally, because of this extensive preparation, they are not practical for routine monitoring of sewage effluent. Despite all of these difficulties, this technique is still the most effective because it makes plume detection easier and usually allows for the quantitative estimation of dilution far away from the diffuser. The possibility of using the tracer detection at very low levels also means that it can be used to investigate high dilution effuents.

\section{Autonomous Underwater Vehicles}

Autonomous underwater vehicles (AUVs) have been used efficiently in a wide range of applications. They were first developed with military applications in mind; for example, for mine hunting missions. Later on, scientists realized their true potential and started to use them as mobile sensors, taking measurements in difficult scenarios and at a reasonable cost. There is currently increasing worldwide interest in the design and implementation of AUVs. With improvements in the vehicles' reliability and communication technology, several scientific missions have been carried out, which have provided high-quality data and therefore revealed the advantages of using these vehicles. For example, the temperature and salinity data collected by ODYSSEY II AUV (designed at the Massachusetts Institute of Technology) (Bellingham et al., 1992; Bellingham, 1997) in Haro Strait, British Columbia, agreed with those obtained using a traditional CTD (conductivity, temperature, and depth) (Nadis, 1997). The British Autosub AUV has been used to assess fish stocks, to evaluate the extent to which fish avoid ocean-going research vessels (Fernandes et al., 2000), and to examine spatial variability in the vicinity of the Bermuda Testbed Mooring sire (Griffiths et al., 2000). More recently, another ODYSSEY AUV was deployed in Massachusetts and the Cape Cod bays to collect chlorophyll fluorescence, optical backscattering $(880 \mathrm{~nm}$ ), and physical data (Robinson et al., 1999; Yu et al., 2002). Several operational missions measuring the behavior of a rhodamine dye plume were performed with a REMUS (remote environmental measuring units) AUV at San Clemente Island and Duck, North Carolina, in March 2001 (Fletcher, 2001). The REMUS vehicle, which was fitted with a rhodamine fluoromerer to measure the dye concentrations in the water column, performed several successful runs both in the near and far field.

\section{MARES AUV}

MARES (modular autonomous robot for environment sampling) AUV has been successfully used to monitor sea outfalls discharges (Abreu et al., 2010a) (see Figure 1).

MARES is $1.5-\mathrm{m}$ long, has a diameter of 8 inches, and weighs about $40 \mathrm{~kg}$ in air. It features a plastic hull with a dry mid body (for electronics and batteries) and additional rings to accommodate sensors and actuators. Its modular structure simplifies the

\section{FIGURE 1}

AUV MARES.

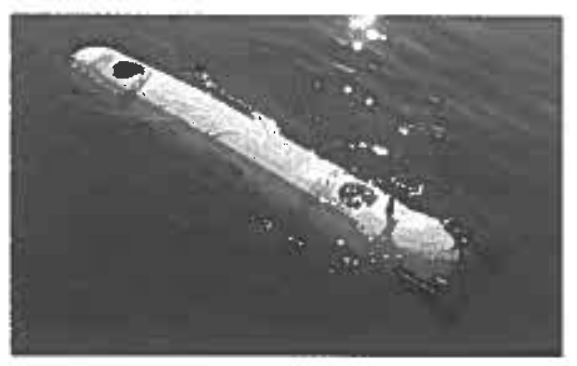


system's development (the case of adding sensors, for example). It is propelled by two horizontal thrusters located at the rear and two vertical thrusters, one at the front and the other at the rear. This configuration allows for small operational speeds and high maneuverability, including pure vertical motions. It is equipped with an omnidirectional acoustic transducer and an electronic system that allows for long baseline navigation. The vehicle can be programmed to follow predefined trajectories while collecting relevant data using the onboard sensors. A Sea-Bird Electronics 49 FastCAT CTD had already been installed onboard the MARES AUV to measure CTD. MARES' missions for environmental monitoring of wastewater discharges are conducted using graphical user interface software that fully automates the operational procedures of the campaign (Abreu et al., 2010a). By providing visual and audio information, this software guides the user through a series of steps, which include (a) real-time data acquisition from CTD and acoustic Doppler current profiler (ADCP) sensors, (b) effluent plume parameter modeling using the CTD and ADCP data collected, (c) automatic path creation using the plume model parameters, (d) acoustic buoys and vehicle deployment, (e) automatic acoustic network setup, and (f) real-time tracking of the AUV mission.

\section{Data Processing}

Data processing is the last step of a sewage outfall discharge monitoring campaign. This processing involves the ability to extrapolate from monitoring samples to unsampled locations. Geostatistical methods have been successfully used to analyze and characterize the spatial variability of soil properties, to obtain information to assess water and wind resources, to design sampling strategies to monitor estuarine sediments, to study the thickness of effluent-affected sediment in the vicinity of wastewater discharges, and to obtain information about the spatial distribution of sewage pollution in coastal sediments. As well as giving the estimated values at unsampled locations, geostatistics provides a measure of the accuracy of the estimate in the form of the kriging variance. This is one of the advantages of geostatistics over traditional methods of pollution assessment. In this work, ordinary block kriging is be used to model and map the spatial distribution of remperature measurements gathered by the AUV on a Portuguese sea outfall monitoring campaign. The aim is to distinguish the effluent plume from the receiving waters and characterize its spatial variability in the vicinity of the discharge.

\section{Geostatistical Analysis}

The ordinary kriging method is often referred to using the acronym BLUE, which stands for best linear unbiased estimator. It is linear because its estimates are weighted linear combinations of the available data. It is unbiased since it expects the estimation error to be equal to 0 , and it is best because it aims to minimize the variance of the errors. In order to estimate the unknown value at any point, the model is a random stationary function that consists of $n+1$ random variables (with the same probability law), one for the value at each of the $n$ sample locations, $Z\left(x_{1}\right), Z\left(x_{2}\right), \ldots, Z\left(x_{n}\right)$, and one for the unknown value at the point that is being estimated $Z\left(x_{0}\right)$ (Cressie, 1993; Isaaks \& Srivastava, 1989). The estimate of $Z\left(x_{0}\right)$ is defined as a weighted linear combination of the random variables at the $n$ sampled locations:

$\hat{Z}\left(x_{0}\right)=\sum_{i=1}^{n} W_{i} \cdot Z\left(x_{i}\right)$

Assuming that all random variables have the same expected value, $m$, the expected value of the estimation error is

$$
E\left[\varepsilon\left(\boldsymbol{x}_{0}\right)\right]=E\left[Z\left(\boldsymbol{x}_{0}\right)-\hat{Z}\left(\boldsymbol{x}_{0}\right)\right]=m\left(1-\sum_{i=1}^{n} w_{i}\right)
$$

Setting this expected value to 0 , to ensure an unbiased estimate, results in

$$
\sum_{i=1}^{n} w_{i}=1
$$

Assuming that all random variables have the same variance, $\sigma^{2}$, the variance of the estimation error is

$$
\operatorname{var}\left[\varepsilon\left(x_{0}\right)\right]=\sigma^{2}-2 \sum_{i=1}^{n} w_{i} C_{i 0}+\sum_{i=1}^{n} \sum_{j=1}^{n} w_{i} w_{j} C_{i j}
$$

where $C_{i 0}=\operatorname{cov}\left[Z\left(x_{i}\right), Z\left(x_{0}\right)\right]$ and $C_{i j}=\operatorname{cov}\left[Z\left(x_{i}\right), Z\left(x_{j}\right)\right], i, j=1,2, \ldots, n$. 
The minimization of the error variance, constrained by the unbiasedness condition (3), is solved using the Lagrange multipliers method, which produces the following system of equations:

$$
\underbrace{\left[\begin{array}{cccc}
C_{11} & \cdots & C_{1 n} & 1 \\
\vdots & \vdots & \ddots & \vdots \\
C_{n 1} & \cdots & C_{n n} & 1 \\
1 & \cdots & 1 & 0
\end{array}\right]}_{(n+1) \times(n+1)} \cdot \underbrace{\left[\begin{array}{c}
w_{1} \\
\vdots \\
w_{n} \\
\mu
\end{array}\right]}_{(n+1) \times 1}=\underbrace{\left[\begin{array}{c}
C_{10} \\
\vdots \\
C_{n 0} \\
1
\end{array}\right]}_{(n+1) \times 1} .
$$

The set of weights $w_{1}, \ldots, w_{n}$ and the Lagrange multiplier $\mu$ that will produce an unbiased estimate of $Z\left(x_{0}\right)$ with the minimum error variance are then given by

$W=C^{-1} \cdot D$

Therefore, the minimized error variance, usually called the ordinary kriging variance, is given by

$\operatorname{var}\left[\varepsilon\left(\boldsymbol{x}_{0}\right)\right]=\sigma^{2}-\boldsymbol{W}^{T} \cdot \boldsymbol{D}$.

Assuming that the random funcrion is stationary, all pairs of random variables, separated by a distance and direction $\boldsymbol{b}$ (known as lag), have the same joint probabiliry distribution. Therefore, the covariance function is (Cressie, 1993; Isaaks \& Srivastava, 1989)

$C(h)=E[Z(\boldsymbol{x}) Z(\boldsymbol{x}+\boldsymbol{h})]-\{E[Z(\boldsymbol{x})]\}^{2}$.

Geostatisticians usually define the spatial continuity of the sample data set using the semivariogram or simply a variogram, which is defined as

$\gamma(h)=\frac{1}{2} E\left[\{Z(x)-Z(x+h)\}^{2}\right]=\frac{1}{2} \operatorname{var}[Z(x)-Z(x+h)]$,

and solve the system of equations (5) using the following relation:

$\gamma(\boldsymbol{h})=C(\boldsymbol{O})-C(\boldsymbol{h})=\sigma^{2}-C(\boldsymbol{h})$.

The widely used estimator of the variogram, known as Matheron's method-of-moments estimator (MME), is (Matheron, 1965)

$\gamma(h)=\frac{1}{2 N(h)} \sum_{i=1}^{N(h)}\left[Z\left(x_{i}\right)-Z\left(x_{i}+h\right)\right]^{2}$

where $Z\left(x_{i}\right)$ is the value of the variable of interest at location $x_{i}$ and $N(b)$ is the number of pairs of points separated by the particular lag $\boldsymbol{b}$. Cressie and Hawkins developed an estimator of the variogram that should be robust to the presence of outliers 
and enhance the variogram's spatial continuity. It also has the advantage of not spreading the effect of outliers when computing the maps. This Cressie estimator (CRE) is defined as follows (Cressie \& Hawkins, 1980):

$\gamma(\boldsymbol{h})=\frac{1}{2} \times \frac{\left\{\frac{1}{N(\boldsymbol{h})} \sum_{i=1}^{N(h)}\left|Z\left(\boldsymbol{x}_{i}\right)-Z\left(\boldsymbol{x}_{i}+\boldsymbol{h}\right)\right|^{1 / 2}\right\}^{4}}{0.457+\frac{0.494}{N(\boldsymbol{h})}+\frac{0.045}{[N(\boldsymbol{h})]^{2}}}$.

Once the variogram has been calculated, a function must be fit to it. The most commonly used variogram models are the spherical model, the exponential model, the Gaussian model, and the Marern model (Isaaks \& Srivastava, 1989).

Cross-validation is a procedure that is used to compare the performance of several competing models. It starts by splitting the data set into two sets: a modeling set and a validation set. The modeling set is then used for variogram modeling and kriging on the locations of the validation set. Finally, the observations of the validation set are compared with their predictions using the following standard measures (Isaaks \& Srivastava, 1989):

$\mathrm{ME}=\frac{1}{m} \sum_{i=1}^{m}\left[Z\left(\boldsymbol{x}_{i}\right)-\hat{Z}\left(\boldsymbol{x}_{i}\right)\right] \quad \mathrm{RMSE}=\sqrt{\frac{1}{m} \sum_{i=1}^{m}\left[Z\left(\boldsymbol{x}_{i}\right)-\hat{Z}\left(\boldsymbol{x}_{i}\right)\right]^{2}} \quad$ MSSE $=\frac{1}{m} \sum_{i=1}^{m} \frac{\left[Z\left(\boldsymbol{x}_{i}\right)-\hat{Z}\left(\boldsymbol{x}_{i}\right)\right]^{2}}{\sigma_{R\left(x_{i}\right)}^{2}}$

The mean error (ME) should be close to 0, the root mean square error (RMSE) should be as low as possible, and the mean standardized square error (MSSE) should be approximately 1 .

\section{Results \\ Study Site}

The study site is shown in Figure 2. The S. Jacinto outfall is located off the Portuguese west coast near to the Aveiro estuary. The total length of the outfall, including the diffuser, is $3378 \mathrm{~m}$ (the first $3135-\mathrm{m}$ section has a diameter of $1600 \mathrm{~mm}$, and the last $243-\mathrm{m}$ section has a diameter of $1200 \mathrm{~mm}$ ). The diffuser, which consists of 72 ports alternating on each side, nominally $0.175 \mathrm{~m}$ in diameter, is $332.5-\mathrm{m}$ long. Currently, only the last 20 of the 72 ports are working in a length of $98.2 \mathrm{~m}$. These are discharging upwards at an angle of $30^{\circ}$ to the horizontal axis; the port height is about $1.3 \mathrm{~m}$. The outfall has a true bearing direction of $290^{\circ}$ and is discharging at a depth varying between approximately 14 and $17 \mathrm{~m}$. The sea floor near to the diffuser is moderately sloped, with a sandy bottom and isobaths that are parallel to the coastline. In that area, the coastline itself runs at about a $200^{\circ}$ angle with respect to true north. Flow variation through the outfall in question is not typical of WWTPs since the effluent is mainly of industrial origin. Effluent flowrate ranges most frequently between 0.6 and $0.8 \mathrm{~m}^{3} / \mathrm{s}$. During the campaign, the discharge remained fairly constant with an average flowrate of approximately $0.61 \mathrm{~m}^{3} / \mathrm{s}$. Figure 2 shows a plan view of the AUV's position estimate during the plume tracking survey. A rectangular area of approximately $200 \times 100 \mathrm{~m}^{2}$ was covered starting $20 \mathrm{~m}$ downstream from the middle point of the outfall diffuser. Temperature measurements were obtained at depths of 2 and $4 \mathrm{~m}$, where the effluent plume was predicted to be horizontally dispersing. In each horizontal trajectory, the vehicle described six parallel transects that were perpendicular to the direction of the current, $200 \mathrm{~m}$ in length and at $20-\mathrm{m}$ intervals. When performing horizontal trajectories, vertical oscillations of the AUV were less than $1 \mathrm{~m}$ (up and down) in the 2-m survey and less than $1 \mathrm{~m}$ down and less than $1.5 \mathrm{~m}$ up in the 4-m survey. In the $2-\mathrm{m}$ trajectory, the average depth of the AUV was $2.0 \mathrm{~m}$ with a standard deviation of $0.20 \mathrm{~m}$. In the 4-m trajectory, the average depth was $4.0 \mathrm{~m}$ with a standard deviation of $0.33 \mathrm{~m}$. During the mission, the vehicle moved at a fairly constant velocity of $1 \mathrm{~m} / \mathrm{s}$ ( 2 knots). Temperature data were recorded at a rate of $2.4 \mathrm{~Hz}$.

The geostatistical analysis was carried out using an application that was developed based on the R statistical software (R Development Core Team, 2009) and on the Gstat package of $R$ (Bivand et al., 2008). This application guides the user through several steps that perform the geostatistical analysis. More details about this software application may be found in Abreu and Ramos (2010b). 


\section{FIGURE 2}

Plan view of the AUV's position estimate during the plume tracking survey (left) and map of the study site (right).
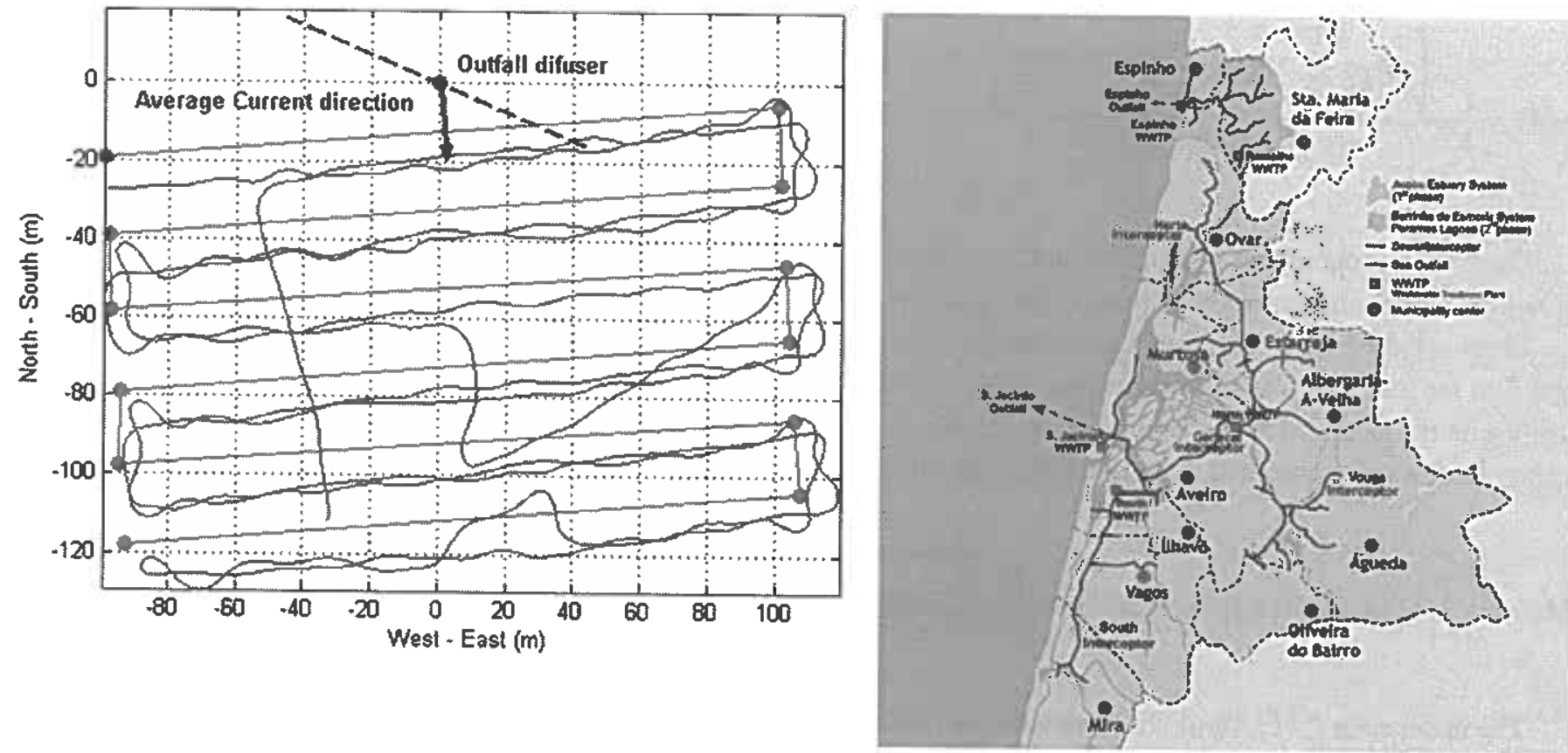

\section{Exploratory Analysis}

In order to obtain elementary knowledge about the temperature data sets, conventional statistical analysis was conducted (see the results in Table 1). At the depth of $2 \mathrm{~m}$, the temperature ranged from $13.64^{\circ} \mathrm{C}$ to $14.63^{\circ} \mathrm{C}$. The mean value of the data set was $14.14^{\circ} \mathrm{C}$, which was very close to the median value that was $14.10^{\circ} \mathrm{C}$. The coefficient of skewness is not very high $(0.70)$, indicating that the distribution is only slightly asymmetric. The very low value of the coefficient of variation ( 0.01$)$ reflects the fact that the histogram does not have a tail of high values. At the depth of $4 \mathrm{~m}$, the temperature ranged from $13.03^{\circ} \mathrm{C}$ to $14.61^{\circ} \mathrm{C}$. The mean value of the data set was $13.76^{\circ} \mathrm{C}$, which was quite close to the median value that was $13.74^{\circ} \mathrm{C}$. The coefficient of skewness is close to zero (0.19), indicating that the histogram

\section{TABLE 1}

Summary statistics of temperature measured at depths of 2 and $4 \mathrm{~m}$.

\begin{tabular}{l|l|l}
\hline & Temperature $(2 \mathrm{~m})$ & Temperature $(\mathbf{4 ~ m})$ \\
\hline Samples & 2,426 & 2.803 \\
\hline Mean & $14.14^{\circ} \mathrm{C}$ & $13.76^{\circ} \mathrm{C}$ \\
\hline Median & $14.10^{\circ} \mathrm{C}$ & $13.74^{\circ} \mathrm{C}$ \\
\hline Minimum & $13.64^{\circ} \mathrm{C}$ & $13.03^{\circ} \mathrm{C}$ \\
\hline Maximum & $14.63^{\circ} \mathrm{C}$ & $14.61^{\circ} \mathrm{C}$ \\
\hline Coefficient of skewness & 0.70 & 0.19 \\
\hline Coefficient of variation & 0.01 & 0.03 \\
\hline
\end{tabular}

is approximately symmetric. This can also be confirmed by the coefficient of variation which is also very low (0.01). The ordinary kriging method works better if the distribution of the data values is close to a normal distribution. Therefore, it is interesting to see how close the distribution of the data values comes to being normal. Figure 3 shows the plots of the normal distribution adjusted to the histograms of the remperature measured at depths of 2 and $4 \mathrm{~m}$. Apart from some erratic high values, it can be seen that the histograms are reasonably close to the normal distribution.

\section{Variogram Modeling}

For the purpose of this analysis, the temperature measurements were divided into a modeling set (comprising $75 \%$ of the samples) and a validation set (comprising 25\% of the samples).

Modeling and validation sets were then compared, in terms of their 


\section{FIGURE 3}

Histograms of temperature measurements at depths of $2 \mathrm{~m}$ (left) and $4 \mathrm{~m}$ (right).
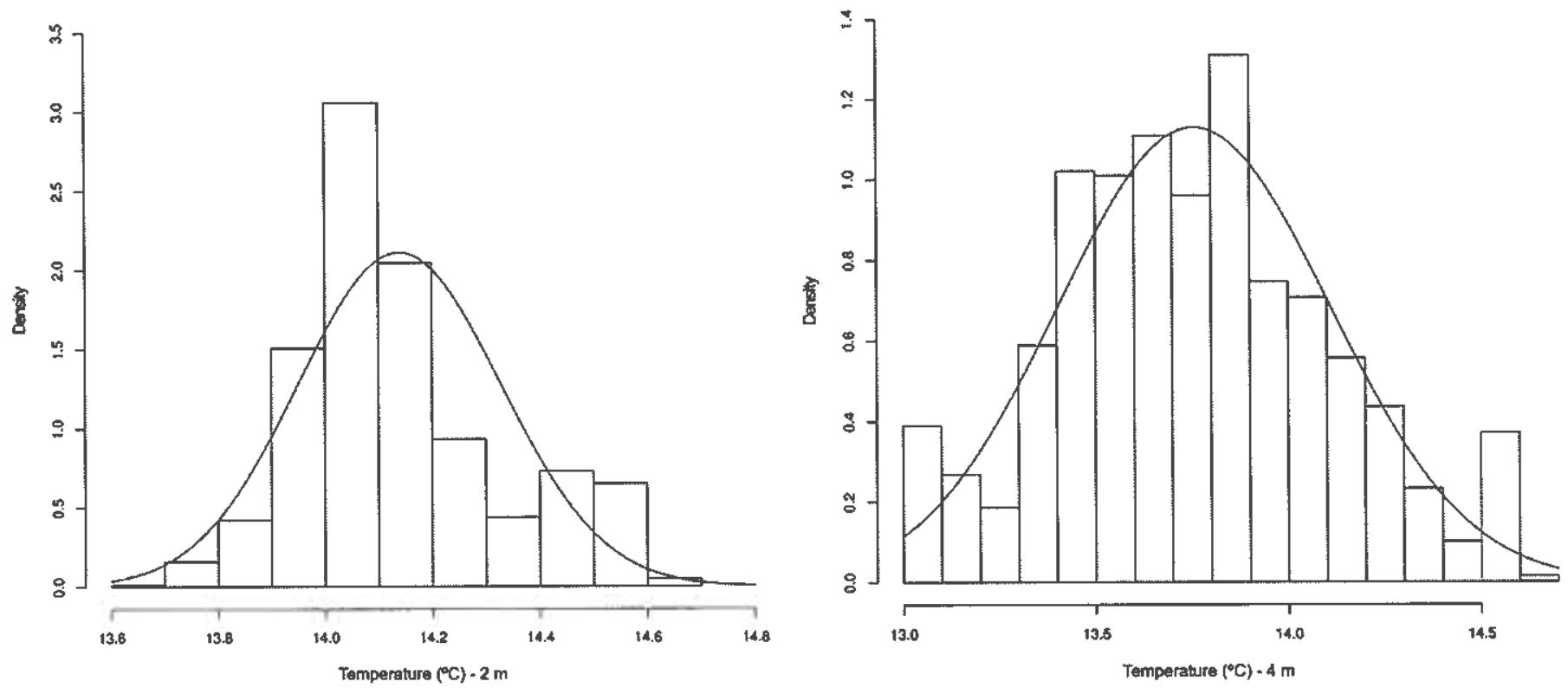

temperature measurements, using Student's $t$ test, to check that they provided unbiased subsets of the original data. Furthermore, sample variograms for the modeling sets were constructed using the MME estimator and the CRE estimator. This robust estimator was chosen to deal with outliers and enhance the variogram's spatial continuity. Figures 4 and 5 show the omnidirectional sample variograms for temperature at the depth of $2 \mathrm{~m}$ using the MME estimator and the CRE estimator, respectively, fitted by
Matern models (for several shape parameters) and by a spherical and an exponential model. Figures 6 and 7 show the omnidirectional sample variograms for temperature at the depth of $4 \mathrm{~m}$ using the MME estimator and the CRE estimator, respectively, fitted

\section{FIGURE 4}

Variogram for temperature at the depth of $2 \mathrm{~m}$ using an MME fitted by Matern models (left) and by a spherical and an exponential model (right).
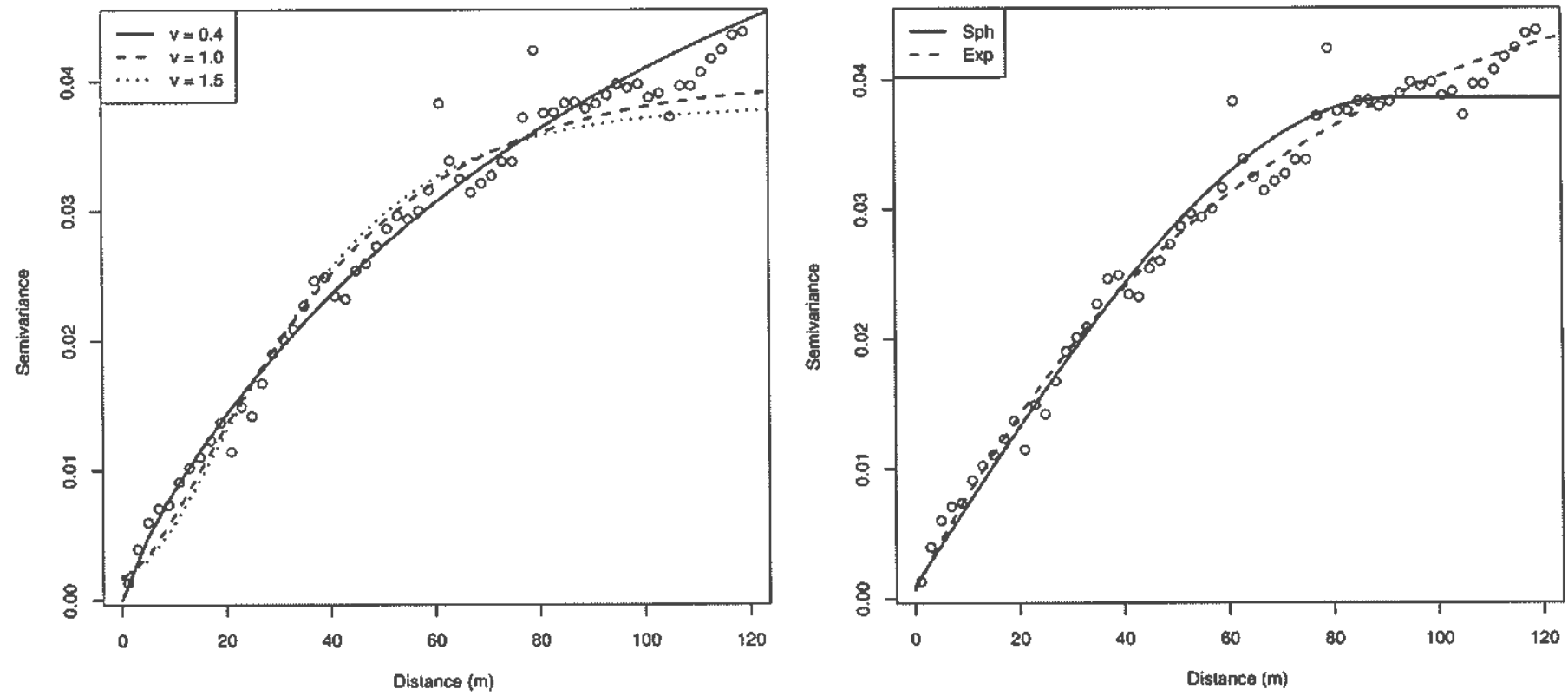


\section{FIGURE 5}

Variogram for temperature at the depth of $2 \mathrm{~m}$ using the CRE estimator fitted by Matern models (left) and by a spherical and an exponential model (right).
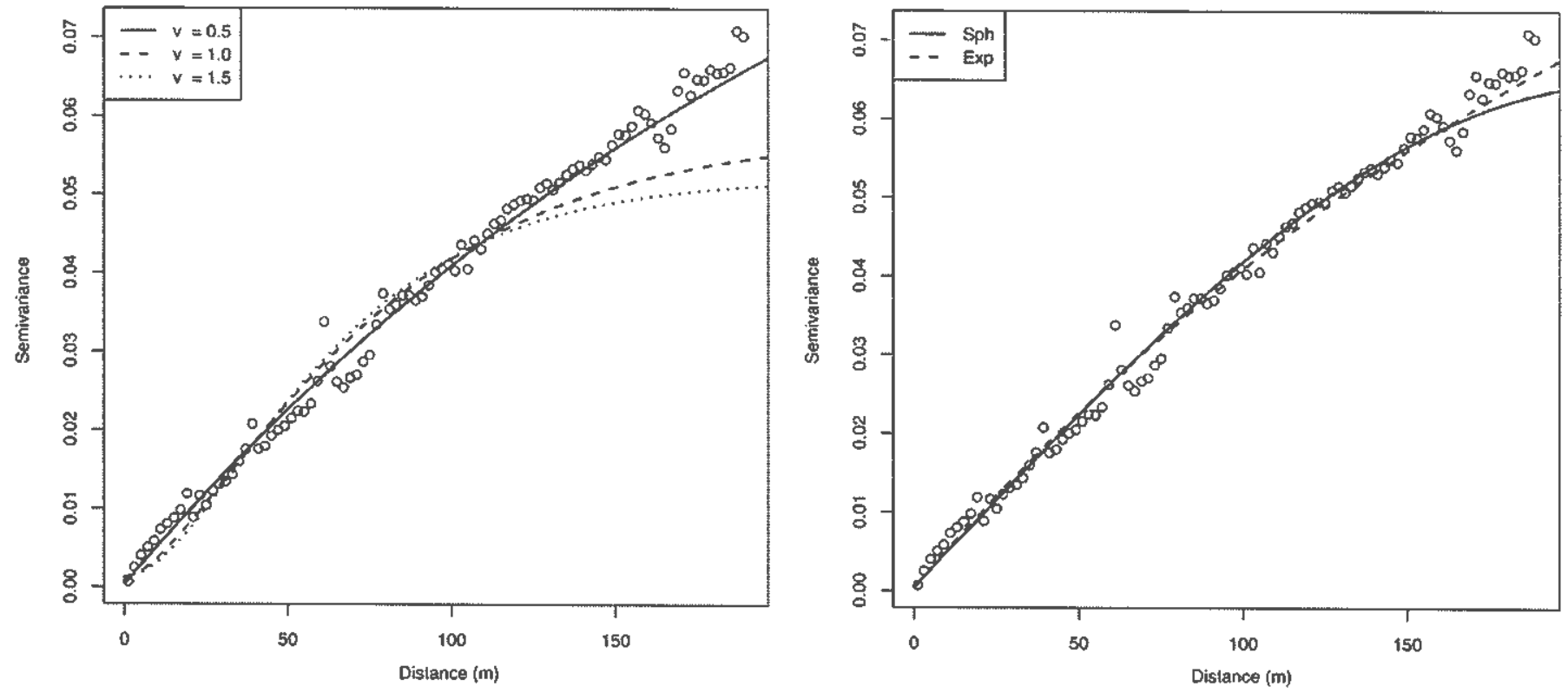

by Matern models (for several shape parameters) and by a spherical and an exponential model. An estimation of semivariance was carried out using a lag distance of $2 \mathrm{~m}$.
The parameters of the fitred models are presented in Tables 2 and 3. The range value is an indicator of extension where autocorrelation exists. The variograms show significant differences in range. For the same model, the autocorrelation distances are always larger for the CRE estimator. The semivariance, $\gamma(\boldsymbol{b})$, estimated by CRE also fluctuates less, demonstrating the

\section{FIGURE 6}

Variogram for temperature at a depth of $4 \mathrm{~m}$ using the MME estimator fitted to Matern models (left) and by a spherical and an exponential model (right).
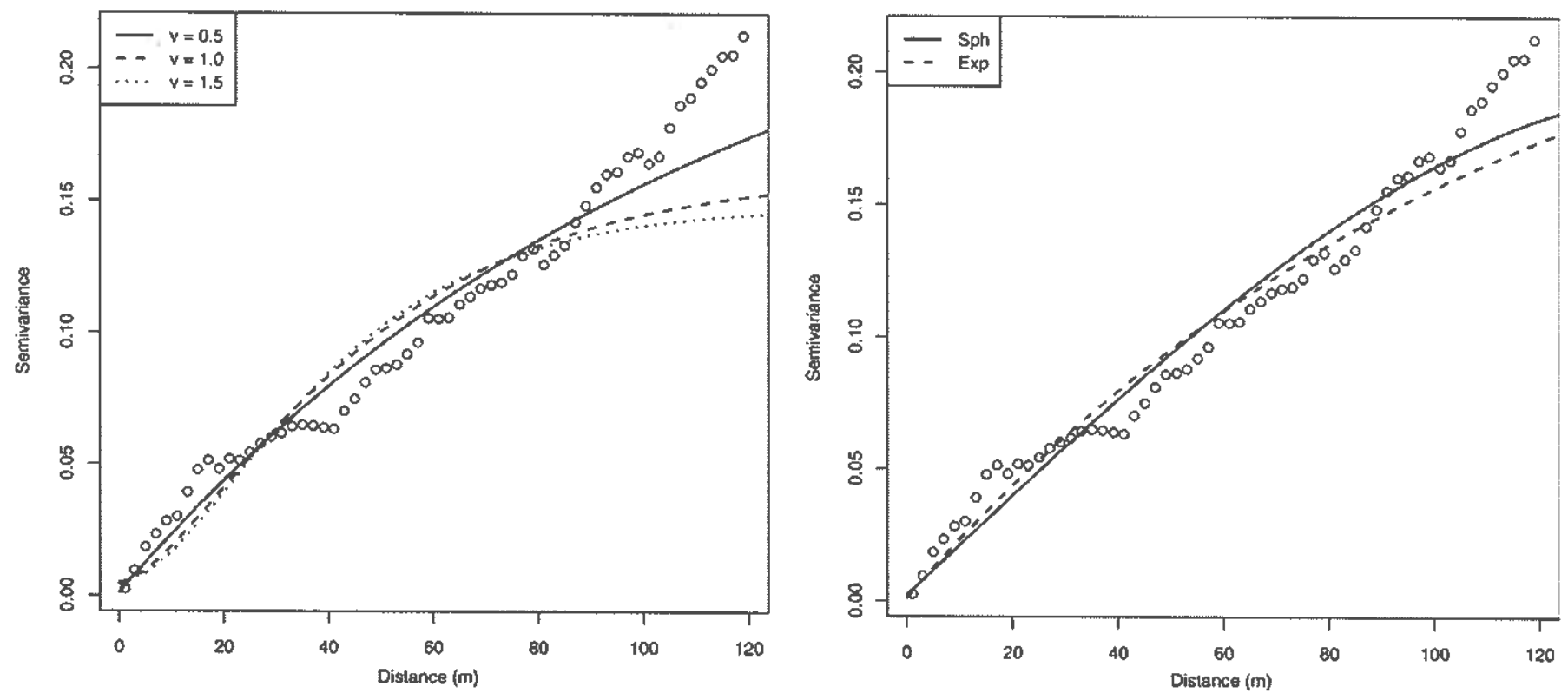

March/April 2011 Volume 45 Number 2 


\section{FIGURE 7}

Variogram for temperature at a depth of $4 \mathrm{~m}$ using the CRE estimator fitted to Matern models.

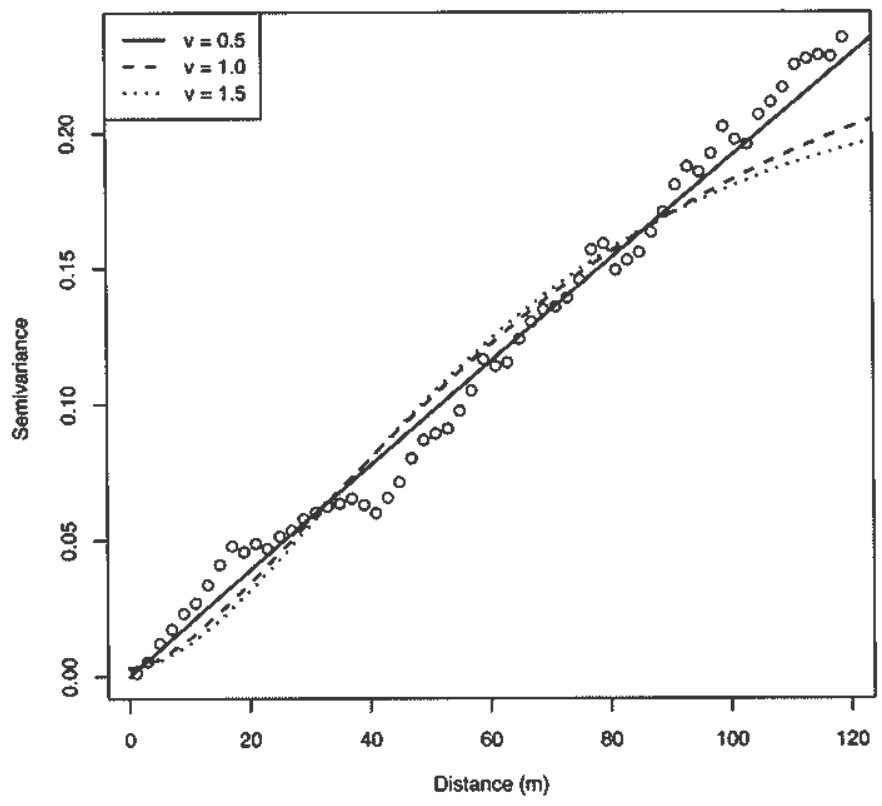

enhancement of the variogram's spatial continuity. All variograms have low nugget values and very low nugget/sill ratios. For all variograms, the nugget/ sill ratio is less than 0.05 . These results indicate that local variations could be captured due to the high sampling rate and to the fact that the variable under study has strong spatial dependence. Anisotropy was investigated by calcu- lating directional variograms. However, no anisotropy effect could be shown.

\section{Cross-Validation}

The block kriging method was preferred since it produced smaller prediction errors and smoother maps than the point kriging. Using the $75 \%$ modeling sets of the two depths, a two- dimensional ordinary block kriging, with blocks of $10 \times 10 \mathrm{~m}^{2}$, was applied to estimate temperature at the locations of the $25 \%$ validation sets. The validation results for the $2-\mathrm{m}$ and 4-m depths are shown in Tables 4 and 5, respectively. At the depth of $2 \mathrm{~m}$, the temperature was best estimated using the Matern model ( $v=$ $0.5)$ with the CRE estimator, while at the depth of $4 \mathrm{~m}$, the temperature was best estimated using the Matern model $(v=1.0)$ and also with the CRE estimator. The difference in performance between the two estimators: block kriging using the MME estimator (MBK) or block kriging using the CRE estimator (CBK), for the several models, is not substantial.

A scatterplot of true versus predicted values provides additional evidence of how well the estimation method has performed. The coefficient of determination, $R^{2}$, is a good index for summarizing how close the points on the scatterplot come to falling on the $45^{\circ}$ line passing through the origin. $R^{2}$ should be close to one. Figure 8 shows the scatterplots of true versus estimated values for the most satisfactory models. These plots

\section{TABLE 2}

Parameters of the fitted variogram models for temperature at the depth of $2 \mathrm{~m}$.

\begin{tabular}{|c|c|c|c|c|c|c|}
\hline Variogram Estimator & Model & Cutoff (m) & Nugget & Sill & $\frac{\text { Muppot }}{\text { Sili }}$ & Range (m) \\
\hline \multirow[t]{5}{*}{ MME } & Matern $(v=0.4)$ & 120 & 0.00000 & 0.063 & 0 & 115.5 \\
\hline & Matern $(v=1.0)$ & 120 & 0.00169 & 0.038 & 0.04 & 25.3 \\
\hline & Matern $(v=1.5)$ & 120 & 0.00186 & 0.036 & 0.05 & 17.9 \\
\hline & Spherical & 120 & 0.00099 & 0.038 & 0.03 & 91.1 \\
\hline & Exponential & 120 & 0.00069 & 0.050 & 0.01 & 63.6 \\
\hline \multirow[t]{4}{*}{ CRE } & Matern $(v=0.5)$ Exponential & 190 & 0.00038 & 0.125 & 0 & 255.6 \\
\hline & Matem $(v=1.0)$ & 190 & 0.00116 & 0.057 & 0.02 & 50.7 \\
\hline & Matern $(v=1.5)$ & 190 & 0.00129 & 0.051 & 0.03 & 33.4 \\
\hline & Spherical & 190 & 0.00049 & 0.064 & 0.01 & 215.7 \\
\hline
\end{tabular}




\section{TABLE 3}

Parameters of the fitted variogram models for temperature at the depth of $4 \mathrm{~m}$.

\begin{tabular}{l|l|l|l|l|l|l}
\hline Variogram Estimator & Model & Cutoff $(\mathbf{m})$ & Nuggel & Sill & $\frac{\text { Augpel }}{\text { sili }}$ & Range $(\mathbf{m})$ \\
\hline \multirow{4}{*}{ MME } & Matern $(v=0.5)$ Exponential & 120 & 0.00120 & 0.267 & 0 & 115.0 \\
\cline { 2 - 7 } & Matern $(v=1.0)$ & 120 & 0.00440 & 0.156 & 0.03 & 31.4 \\
\cline { 2 - 7 } & Matern $(v=1.5)$ & 120 & 0.00500 & 0.143 & 0.03 & 21.4 \\
\cline { 2 - 7 } & Spherical & 120 & 0.00222 & 0.192 & 0.01 & 151.2 \\
\hline \multirow{3}{*}{ CRE } & Matern $(v=0.5)$ Exponential & 120 & 0.00000 & 5.145 & 0 & 2645.3 \\
\cline { 2 - 7 } & Matern $(v=1.0)$ & 120 & 0.00268 & 0.250 & 0.01 & 50.2 \\
\cline { 2 - 7 } & Matern $(v=1.5)$ & 120 & 0.00325 & 0.216 & 0.02 & 32.1 \\
\hline
\end{tabular}

\section{TABLE 4}

Cross-validation results for the temperature map at the depth of $2 \mathrm{~m}$.

\begin{tabular}{l|l|l|l|l|l}
\hline Method & Model & $\boldsymbol{R}^{\mathbf{2}}$ & ME & RMSE & MSSE \\
\hline \multirow{4}{*}{ MBK } & Matern $(v=0.4)$ & 0.9146 & 0.00264 & 0.0541 & 5.5 \\
\cline { 2 - 6 } & Matern $(v=1.0)$ & 0.9125 & 0.00305 & 0.0547 & 17.0 \\
\cline { 2 - 6 } & Matern $(v=1.5)$ & 0.9067 & 0.00314 & 0.0565 & 25.9 \\
\cline { 2 - 6 } & Spherical & 0.9137 & 0.00284 & 0.0544 & 8.5 \\
\cline { 2 - 6 } & Exponential & 0.9150 & 0.00279 & 0.0539 & 7.1 \\
\hline \multirow{4}{*}{ CBK } & Matern $(v=0.5)^{\mathrm{a}}$ Exponential & 0.9154 & 0.00277 & 0.0538 & 11.4 \\
\cline { 2 - 6 } & Matern $(v=1.0)$ & 0.9085 & 0.00307 & 0.0560 & 34.4 \\
\cline { 2 - 6 } & Matem $(v=1.5)$ & 0.8967 & 0.00326 & 0.0595 & 54.6 \\
\cline { 2 - 6 } & Spherical & 0.9148 & 0.00279 & 0.0540 & 12.2 \\
\hline
\end{tabular}

${ }^{\text {a }}$ The preferred model.

\section{TABLE 5}

Cross-validation results for the temperature map at the depth of $4 \mathrm{~m}$.

\begin{tabular}{l|l|l|l|l|l}
\hline Method & Model & $\boldsymbol{R}^{2}$ & ME & RMSE & MSSE \\
\hline \multirow{4}{*}{ MBK } & Matern $(v=0.5)$ Exponential & 0.9471 & -0.00579 & 0.0806 & 6.3 \\
\cline { 2 - 6 } & Matern $(v=1.0)$ & 0.9488 & -0.00617 & 0.0793 & 14.8 \\
\cline { 2 - 6 } & Matern $(v=1.5)$ & 0.9436 & -0.00731 & 0.0833 & 23.2 \\
\cline { 2 - 6 } & Spherical & 0.9460 & -0.00598 & 0.0814 & 7.4 \\
\hline \multirow{2}{*}{ CBK } & Matem $(v=0.5)$ Exponential & 0.9480 & -0.00564 & 0.0799 & 7.9 \\
\cline { 2 - 6 } & Matern $(v=1.0)^{\text {a }}$ & 0.9492 & -0.00630 & 0.0790 & 23.6 \\
\cline { 2 - 6 } & Matern $(v=1.5)$ & 0.9403 & -0.00797 & 0.0856 & 41.2 \\
\hline
\end{tabular}

aThe preferred model. 


\section{FIGURE 8}

Predicted versus observed temperatures at the depths of $2 \mathrm{~m}$ (left) and $4 \mathrm{~m}$ (right) using the preferred models.
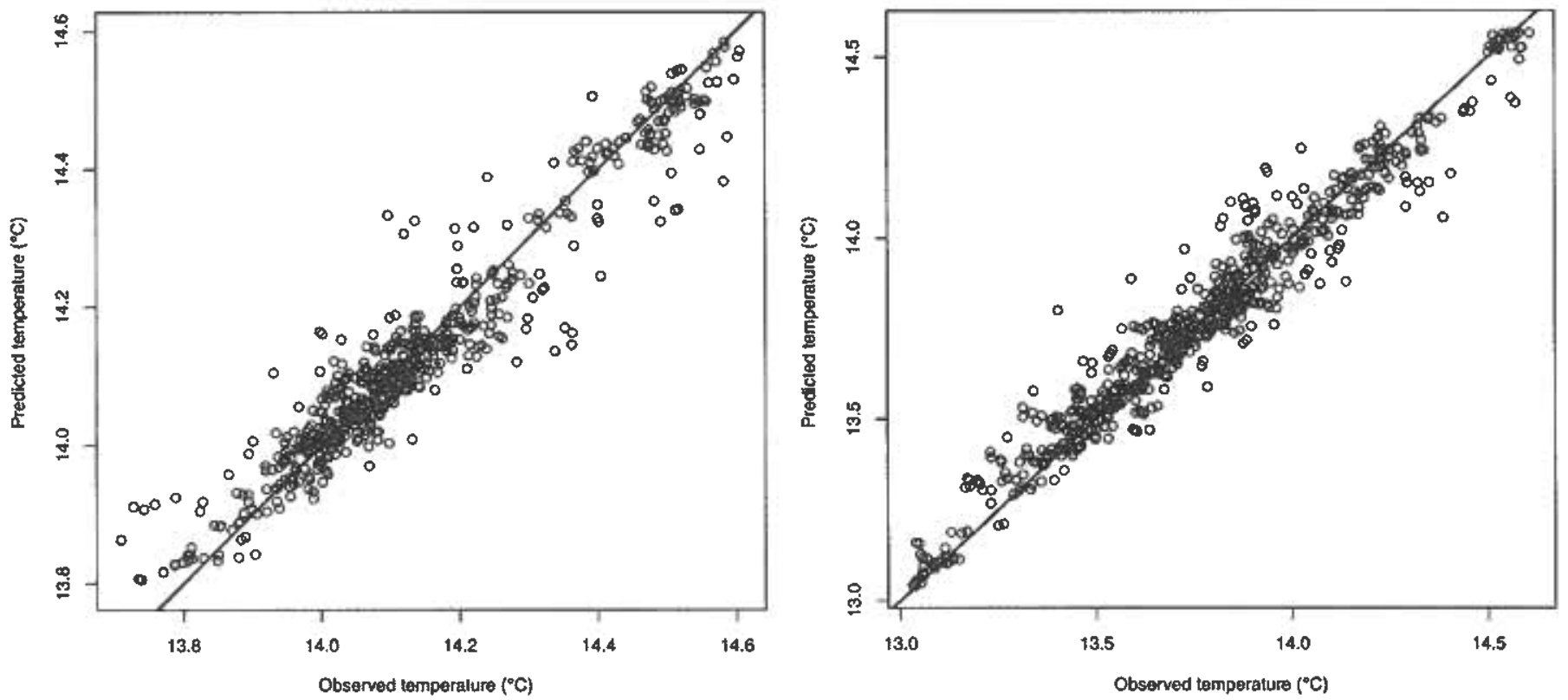

show that observed and predicted values are highly positively correlated. The $R^{2}$ value for the temperature at the depth of $2 \mathrm{~m}$ was 0.9154 , and the RMSE was $0.0538^{\circ} \mathrm{C}$ (Table 4). The $R^{2}$ value for the temperature at the depth of $4 \mathrm{~m}$ was 0.9492 , and the RMSE was $0.0790^{\circ} \mathrm{C}$ (Table 5). The MSSE values are relatively high, proba- bly due to the smoothing effect of the block kriging.

Figures 9 and 10 show the block kriged maps on a $2 \times 2 \mathrm{~m}^{2}$ grid using the preferred models. In the $2-m$ kriged map, the temperature ranges between $13.80^{\circ} \mathrm{C}$ and $14.58^{\circ} \mathrm{C}$ and the average value is $14.15^{\circ} \mathrm{C}$, which is in accordance with the measurements

\section{FIGURE 9}

Prediction map of temperature distribution at the depth of $2 \mathrm{~m}$.

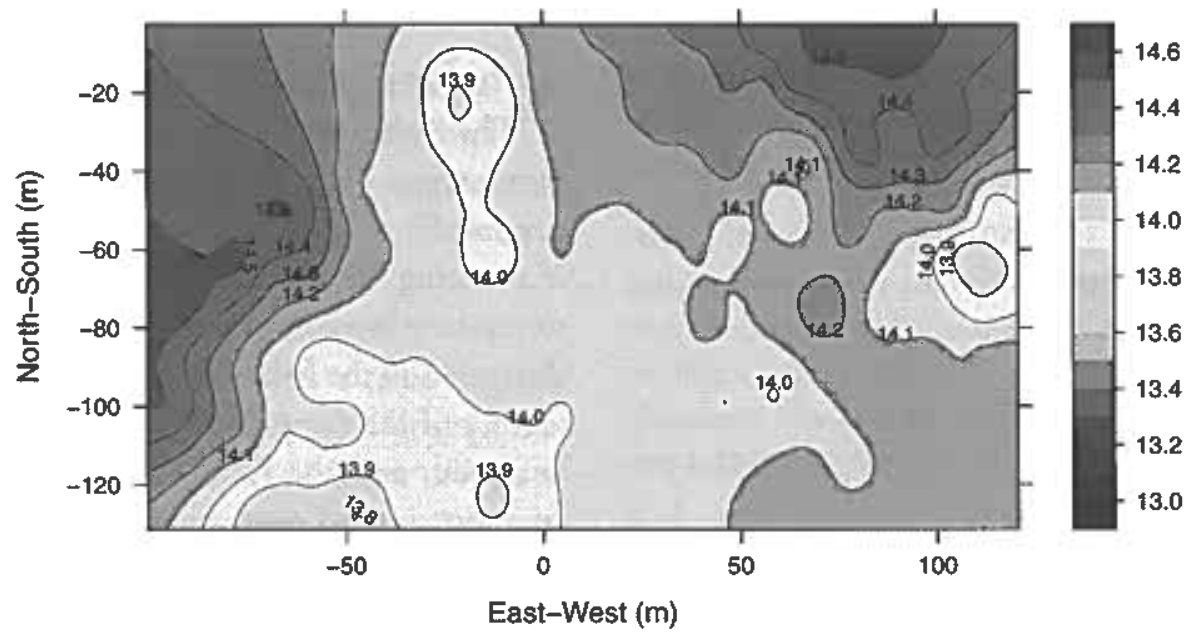

(range, $13.64-14.63^{\circ} \mathrm{C}$ and average, $\left.14.14^{\circ} \mathrm{C}\right)$. In the $4-\mathrm{m}$ kriged map, the temperature ranges between $12.98^{\circ} \mathrm{C}$ and $14.64^{\circ} \mathrm{C}$ and the average value is $13.79^{\circ} \mathrm{C}$, which is in accordance with the measurements (range, $13.03-14.61^{\circ} \mathrm{C}$ and average, $13.76^{\circ} \mathrm{C}$ ). The kriging variance is less than $0.04^{\circ} \mathrm{C}$ in the $2-\mathrm{m}$ map and less than $0.07^{\circ} \mathrm{C}$ in the 4-m map. Figure 11 shows a vertical profile of the background remperature obtained by the AUV at the end of the campaign. The temperature difference between the surface and the bottom was abour $1.5^{\circ} \mathrm{C}$ with most of the difference occurring in a thermocline that extended from 2 to $10 \mathrm{~m}$. This relatively weak stratification explains the plume spreading near the surface, as predicted by a prediction model used in the field to specify the AUV survey. Both maps show the spatial variation of temperature in the area studied. From these maps, it is possible to identify the effluent plume and its dispersion downstream in the direction of the current. 


\section{FIGURE 10}

Prediction map of temperature distribution at the depth of $4 \mathrm{~m}$.

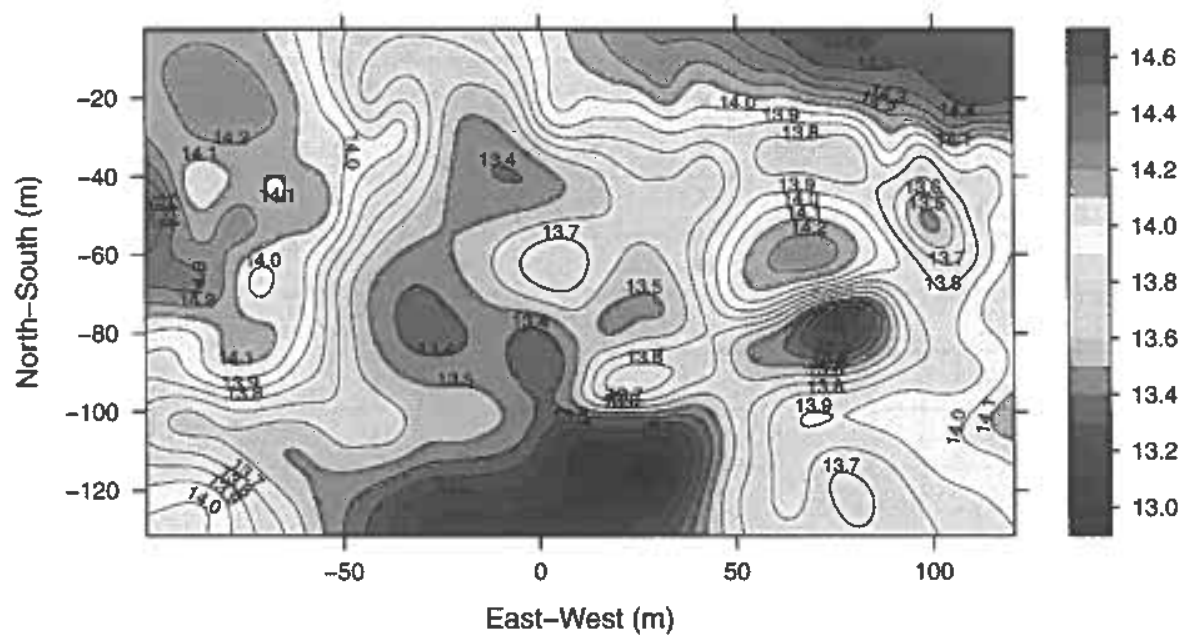

It appears as a region of lower temperature when compared with the surrounding ocean waters at the same depth. When considering maximum vertical oscillations of the AUV in performing the horizontal trajectories, the range of background temperature in the $2-\mathrm{m}$ map is $14.41-14.50^{\circ} \mathrm{C}$, and the range of background temperature in the 4-m map is $14.07-14.46^{\circ} \mathrm{C}$. When taking the kriging variance into account, in the 2-m map, the plume may be identified by the regions where temperature is less than $14.4^{\circ} \mathrm{C}$ and in the $4-\mathrm{m}$ map by the regions where temperature is less than $14.0^{\circ} \mathrm{C}$. The effluent temperature was measured at the discharge chamber near to the shore using a 24 -h composed sample and the average value obtained was $35^{\circ} \mathrm{C}$. This value is not very relevant since the effluent probably cools

\section{FIGURE 11}

Vertical profile of background temperature obtained by the AUV at the end of the campaign.

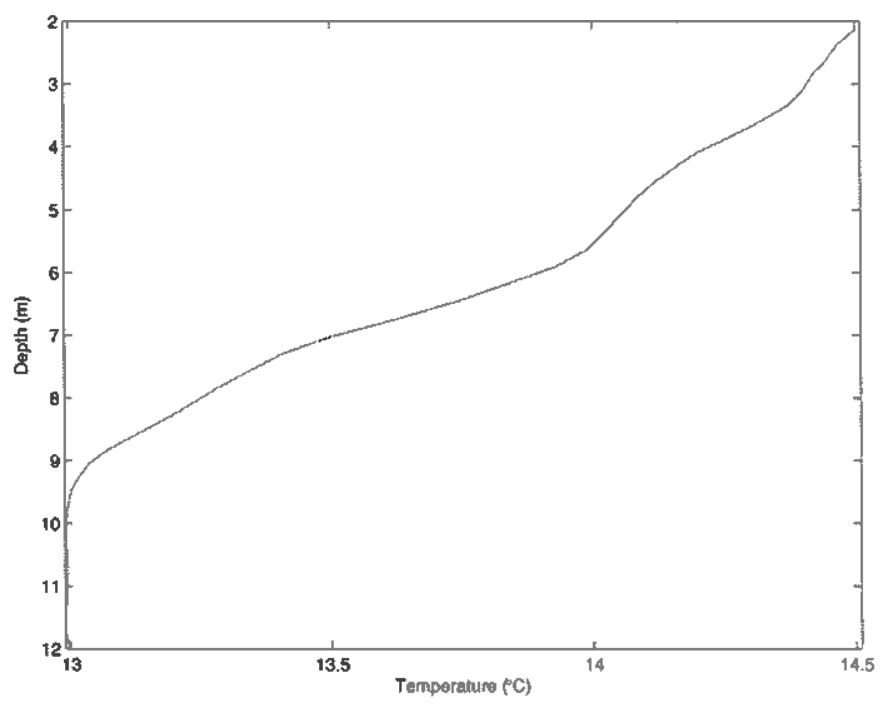

down to the soil temperature of $13^{\circ} \mathrm{C}$ during its trip of about $3.4 \mathrm{~km}$ through the outfall pipe.

At the depth of $2 \mathrm{~m}$, the major difference in temperature compared with the surrounding waters is about $-0.7^{\circ} \mathrm{C}$, while at the depth of $4 \mathrm{~m}$, this difference is about $-1.6^{\circ} \mathrm{C}$. Washburn et al. (1992) observed temperature anomalies in the plume only in the order of $-0.3^{\circ} \mathrm{C}$ when compared with the surrounding waters within the same depth range. The plume exhibits a considerably more complex structure than the compact shape of the classical picture of the buoyant plume and as patchy as in previous studies (Washburn, 1992; Wu et al., 1994; Petrenko et al., 1998). The small plume-related anomalies in the local temperature of Figures 9 and 10 are evidence of the rapid mixing process. Due to the large differences in density berween the rising effluent plume and ambient ocean waters, entrainment and mixing processes are vigorous and the properties within the plume change rapidly (Washburn, 1992). These results therefore confirm that large gradients in background temperature and the small differences in temperature between the effluent plume and the ambient waters can easily obscure the signature of the plume.

\section{Conclusions}

Through geostatistical analysis of temperature obtained by an AUV at depths of 2 and $4 \mathrm{~m}$ in an ocean outfall monitoring campaign, it was possible to produce kriged maps of the sewage dispersion in the field. The spatial variability of the sampled data has been analyzed, and the results indicated an approximated normal distribution of the temperature measurements, which is desirable. The Matheron's 
classical estimator and Cressie and Hawkins' (1980) robust estimator were then used to compute the omnidirectional variograms that were fitted to Matern models (for several shape parameters) and to spherical and exponential models. For the same model, the autocorrelation distances were always larger for the CRE estimator. Semivariance also fluctuated less when estimated by the CRE estimator, demonstrating the enhancement of the variogram's spatial continuity. The performance of each competing model was compared using a splitsample approach. The validation results, using a two-dimensional ordinary block kriging, suggested the Matern model ( $v=0.5$ and $v=1.0$ ) with semivariance estimated by CRE. The difference in performance between the two estimators was not substantial. Block kriged maps of temperature at depths of 2 and $4 \mathrm{~m}$ show the spatial variation of temperature in the area studied, and it is possible to identify the effluent plume that appears as a region of lower temperature when compared with the surrounding waters. These results demonstrate that geostatistical methodology can provide good estimates of the dispersion of effluent that is very valuable in assessing the environmental impact and managing sea outfalls. Moreover, since accurate measurements of the plume's dilution are rare, these studies might be very helpful in the future to validate dispersion models.

\section{Acknowledgments}

This work was supported by project WWECO-Environmental Assessment and Modeling of Wastewater Discharges Using Autonomous Underwater Vehicles Bio-optical Observarions-funded by the Foun- dation for Science and Technology under the Program for Research Projects in all scientific areas (Programa de Projectos de Investigação em todos os domínos científicos) (ref. PTDC/ MAR/74059/2006).

\section{Authors:}

\section{Patrícia Ramos}

Institute for Systems and Computer Engineering of Porto (INESC Porto) Campus da FEUP, Rua Dr. Roberto Frias 378, 4200-465 Porto, Portugal

Tel: +351-22-2094399;

Email: pramos@inescporto.pt

School of Accounting and Administration of Porto/ Polytechnic Institute of Porto Rua Jaime Lopes Amorim s/n, 4465-004 S. Mamede Infesta, Portugal Tel: +351-22-9050000;

Email: patricia@iscap.ipp.pt

\section{Nuno Abreu}

Institute for Systems and Computer Engineering of Porto (INESC Porto) Campus da FEUP, Rua Dr. Roberto Frias 378, 4200-465 Porto, Portugal Tel: +351.22.2094399;

Email: nabreu@inescporto.pt

\section{References}

Abreu, N., Matos, A., Ramos, P., \& Cruz, N. 2010a. Automatic interface for AUV mission planning and supervision. In: Proceedings of MTS/IEEE International Conference Oceans 2010. Seattle, WA: IEEE.

978-1-4244-4333-8/10.

Abreu, N., \& Ramos, P. 2010b. An integrated application for geostatistical analysis of sea outfall discharges based on R software. In: Proceedings of MTS/IEEE International Conference Oceans 2010. Seatule, WA: IEEE. 978-1-4244-4333-8/10.

Bellingham, J. 1997. New oceanographic uses of autonomous underwater vehicles. Mar Technol Soc J. 31(3):34-47.
Bellingham, J., Goudey, C., Consi, T.R, \& Chryssostomidis, C. 1992. A small long range vehicle for deep ocean exploration. In: Proceedings of the International Offshore and Polar Engineering Conference, pp. 151-9. San Francisco, CA: International Sociecy of Offshore and Polar Engineers.

Bivand, R.S., Pebesma, E.J., \& GómezRubio, V. 2008. Applied spatial data analysis with R. Series: Use R, XIV, ISBN: 97-0-387-78170-9, $378 \mathrm{p}$.

Carvalho, J.L.B., Roberts, P.J.W., \& Roldáo, J. 2002. Field observations of the Ipanema Beach outfall. J Hydraul Eng ASCE. 128(2): 151-60. doi: 10.1061/(ASCE)0733-9429 (2002)128:2(151).

Cressie, N. 1993. Statistics for Spatial Data. New York: Wiley Interscience Publication. $900 \mathrm{p}$.

Cressie, N., \& Hawkins, D.M. 1980. Robust estimation of the variogram, I. J Int Assoc Math Geol. 12(2):115-25. doi: 10.1007/ BF01035243.

Fernandes, P.G., Brierley, A.S., Simmonds, E.J., Millard, N.W., McPhail, S.D., Armstrong, F., ... Squires, M. 2000. Fish do not avoid survey vessels. Nature. 404:35-6. doi: $10.1038 / 35003648$.

Fletcher, B. 2001. Chemical plume mapping with an autonomous underwater vehicle. In: Proceedings of the MTS/IEEE International Conference Oceans 2001, pp. 508-12.

Hawaii, USA: IEEE.

Griffiths, G., Knap, A, \& Dickey, T. 2000. Autosub experiment near Bermuda. Sea Technol. $41(2): 35-47$.

Hunt, C.D., Mansfield, A.D., Mickelson, M.J., Albro, C.S., Geyer, W.R., \& Roberts, P.J.W. 2010. Plume tracking and dilution of effluent from the Boston sewage ourfall. Mar Environ Res. IEEE. 70:150-61. doi: $10.1016 /$ j.marenvres.2010.04.005.

Isaaks, E.H., \& Srivastava, R.M. 1989. Applied Geostatistics. New York: Oxford University Press. ISBN 0-19-505012-6-ISBN 0-19-505013-4 (pbk.). 561 p. 
Jones, B.H., Barnett, A., \& Robertson, G.L. 2001. Towed mapping of the effluent plume from a coastal ocean outfall. In: Proceedings of MTS-IEEE International Conference Occans 2001, pp. 1985-9. Hawaii, USA; IEEE. MTS 0-933957-29-7.

Matheron, G. 1965. Les Variables Régionalisees Et Leur Estimation: Une Application de la Théorie des Fonctions Aléaroires Aux Sciences de la Nature. Paris, France:

Masson. 305 p.

Nadis, S. 1997. Real time oceanography adapts to sea changes. Science. 275:1881-2. doi: $10.1126 /$ science. $275.5308 .1881 \mathrm{a}$.

Petrenko, A.A., Jones, B.H., \& Dickey, T.D. 1998. Shape and initial dilurion of Sand Island, Hawaii sewage plume. J Hydraul Eng ASCE. 124(6):565-71, doi: 10.1061/ (ASCE)0733-9429(1998)124:6(565).

Ramos, P., \& Neves, M.V. 2009. Environmental impact assessment and management of sewage outfall discharges using AUVs. In: Underwater Vehicles, ed. Inzartsev, A. In-Tech, Austria: Prentice Hall. ISBN 978-953-7619-49-7.

Ramos, P., Neves, M.V., \& Pereira, F.L. 2007. Mapping and initial dilution estimation of a sewage outfall plume using an auronomous underwater vehicle. Cont Shelf Res. 27:583-93. doi: 10.1016/j.csr.2006.11.017.

R Development Core Team. 2009.

R: A language and environment for statistical computing and graphics. hrtp://www. r-project.org, R Foundation for staristical computing (accessed 28 February 2011).

Roberts, P.J.W., Hunt, C.D., \& Mickelson, M.J. 2002. Field and model studies of the Boston ourfall, In: Proceedings of the 2nd International Conference on Marine Waste Water Discharges MWWD 2002, pp. 16-20. Istanbul, Turkey: MWWD Organization.

Robinson, A, Bellingham, J., Chryssostomidis, C., Dickey, T., Levine, E., Petrikalakis, N., ... Atwood, D.1999. Real-time forecasting of the multidisciplinary coastal ocean with the littoral ocean observing and predicting system (LOOPS). In; Proceedings of the Third
Conference on Coastal Armospheric and Oceanic Prediction Processes. New Orleans, LA: American Mereorological Sociery.

Washburn, L., Jones, B.H., Bratkovich, A., Dickey, T.D., \& Chen, M.-S. 1992. Mixing, dispersion, and resuspension in vicinity of ocean wastewater plume. J Hydraul Eng ASCE. 118(1):38-58. doi: 10.1061/ (ASCE)0733-9429(1992)118:1(38).

Wu, Y., Washburn, L., \& Jones, B.H. 1994. Buoyant plume dispersion in a coastal environment: evolving plume structure and dynamics. Cont Shelf Res. 14(9):1001-23. doi: 10.1016/0278-4343(94)90061-2.

Yu, X, Dickey, T., Bellingham, J., Manov, D., \& Streirlien, K. 2002. The application of autonomous underwarer vehicles for interdisciplinary measurements in Massachusetts and Cape Cod bays. Cont Shelf Res. 22(15):2225-45. doj: 10.1016/\$0278-4343(02)00070-5. 